\title{
Post-traumatic posterior heel soft tissue defect reconstruction
}

\author{
M. P. Suri, A. G. Patel, H. J. Vora, S. C. Raibagkar, D. R. Mehta, U. H. Vyas \\ The Department of Plastic Surgery, Smt . Shardaben Chimanlal Municipal Hospital, Saraspur, Sheth K.M. Institute of Post \\ Graduate Studies, N. H. L Medical College, Ahmedabad, Gujarat, India
}

Address for correspondence: Dr. U.H. Vyas, 1, Hatkesh Society, Darpan Five Roads, St. Xavier's High School Road, Ahmedabad-380 014, Gujarat, India. E-mail:druhv_shardaben@yahoo.co.in

\begin{abstract}
We present a simple algorithm for management of post-traumatic posterior heel defect. We covered these with various flaps depending upon the defect size, its exact location, associated injuries, extent of zone of trauma, and complexity of the defect. The aim was to select the most suitable method for soft tissue coverage for posterior heel reconstruction.
\end{abstract}

\section{KEY WORDS}

Post-traumatic, Posterior heel defects, Coverage

\section{INTRODUCTION}

-

he reconstruction of soft tissue defects of the posterior heel (non-weight bearing part of the heel around the tendoachilles region or those involving weight-bearing) presents challenging problems for plastic surgeons. Soft tissues defects, whether from recent trauma or from chronic lesions are difficult to cover and require a well vascularised reconstruction having a good durability and sensation because of its location and repeated friction by footwear.

However, with a better understanding of the vascular anatomy of the leg and the availability of microsurgical techniques, flaps can be chosen that are easy to execute quickly and provide durable coverage for the defect. They include local flaps: perforator based flaps and lateral calcaneal artery flaps, regional flaps: distally based sural artery flap, distally based fasciocutaneous posterior calf flap and distant flap: cross leg flap and micro vascular flaps. Simple method like skin grafting may also be useful in specific situations.

This study was carried out to select the most suitable method of reconstruction and to present a simple algorithm for management for various post-traumatic posterior heel defects, isolated or combined. This helped to select the method with least morbidity of recipient and donor site and best possible way of rehabilitation of the patient.

\section{MATERIALS AND METHODS}

We present a simple algorithm for management, of posttraumatic posterior heel defects through a study carried out in 50 cases from March 2001 to February 2005. Patient's data including age, sex, side of injury, mode of injury, extent of injury (isolated or combined), if combined whether involving the weight-bearing part of heel, type of wound, 
management of wound, wound healing time and complications were noted. Thorough wound toilet and debridement, fixation of fractures (if required done by orthopedic unit) and immobilization was done. Paraffin gauze dressing was done, and limb elevation was given, daily dressings were carried out and coverage was given with Split thickness skin graft or flap. Most of the patients were operated under spinal anesthesia (except free flaps and few other patients). Immobilization was done depending upon the flap, but in most of the instances dorsal below knee slab was given.

Isolated injuries (injuries only over the posterior heel) were present in 39 patients (78\%) and combined injuries (injuries to posterior heel and surrounding regions) in 11 patients (22\%) [Table 1]. Isolated injuries were covered with Split thickness skin grafting $(n=18)$, Lateral calcaneal artery flap $(n=12)$, distally based superficial sural artery flap $(n=6)$, Free flap $(n=2)$ and Perforator based flap $(n=1)$. Combined injuries were covered with, distally based fasciocutaneous posterior calf flap $(n=4)$, distally based superficial sural artery flap $(n=3)$, Cross leg flap $(n=2)$ and Split thickness skin grafting $(n=2)$ [Table 1]. Six of the injuries occurred involving the posterior heel and weight-bearing part of the heel (combined injuries) which were covered with the Split thickness skin grafting in two of the patients, distally based superficial sural artery flap in two of the patients and crossleg flap in two of the patients.

Pressure dressings (Elastocrepe bandage) was started on the $10^{\text {th }}$ day with gradual dependency (if no complications) started on the between 12 to 15 days and increasing it till the $21^{\text {st }}$ day. Active and passive physiotherapy of joints around ankle was also started on the $10^{\text {th }}$ day. After 21 days gradual mobilization was started with intermittent weight bearing, making the patient to do all his activities at around one and half months. In between the weight bearing, patients were advised elevation of limbs. Patients were also advised to keep a constant watch over the graft for congestion and breakage and in flaps, for congestion and softening. Daily massage and use of special footwear (silicone) were also explained to the patient.

Follow-up was carried out for the presence of pain over the donor or recipient site, aesthetic appearance of donor and recipient site, loss and restriction of movements, loss of sensations by division of sural nerve or superficial peroneal nerve and scar complications. In the patients having injury over the weight bearing part of the heel, protective special footwear were advised. Average followup of the patients was 13.3 months and longest follow-up was 4 years.

\section{RESULTS}

The patients studied were between 3 and 80 years of age, with a mean age of 24.08 years and with a preponderance of male patients (66\%). Right foot was involved in more number of patients $(70 \%)$ as compared to left $(30 \%)$. The mode of injury was road traffic accidents (44\%), Spoke wheel injuries (38\%), Railway tract injuries (4\%) and others [Figure 1].

Exposed Tendoachilles (even if partially cut) or bone [Table 2] was present in $60 \%(n=30)$ of the patients, which required flap coverage. Fracture calcaneum was present in two of the patients; one of the patients was managed by posterior slab and other by thick K-wire by the orthopedic

Table 1: Method of reconstruction

\begin{tabular}{|c|c|c|c|}
\hline Method of reconstruction & Type of injury & Frequency of reconstruction & Complications \\
\hline \multirow[t]{2}{*}{ Lateral calcaneal artery flap } & Isolated & 12 & Minimal donor site graft loss (5 patients) \\
\hline & Combined & 0 & - \\
\hline $\begin{array}{l}\text { Distallybased superficial } \\
\text { sural artery flap }\end{array}$ & Isolated & 6 & Distal flap necrosis (2 patients) \\
\hline \multirow{2}{*}{$\begin{array}{l}\text { Distally based fasciocutaneous } \\
\text { posterior calf }\end{array}$} & Isolated & 0 & - \\
\hline & Combined & 4 & $\begin{array}{c}\text { Distal flap necrosis ( } 2 \text { patients \& Minimal donor } \\
\text { site graft loss ( } 1 \text { patient) }\end{array}$ \\
\hline \multirow[t]{2}{*}{ Perforator based flap } & Isolated & 1 & Nil \\
\hline & Combined & 0 & - \\
\hline \multirow[t]{2}{*}{ Split thickness skin graft } & Isolated & 18 & Partial graft loss (1 patient) \\
\hline & Combined & 2 & Partial graft loss (2 patients) \\
\hline Cross leg flap & Isolated & 0 & - \\
\hline
\end{tabular}


Table 2: Complexity of injury

\begin{tabular}{|c|c|c|}
\hline Complexity of injury & lumber of patients & Method of reconstruction \\
\hline Exposed Tendoachilles & 19 & $\begin{array}{l}\text { 2Free flaps, } 9 \text { Lateral calcaneal artery flap, } 6 \text { Distally based superficial } \\
\text { sural artery flap, } 1 \text { Distally based fasciocutaneous posterior calf flap and } \\
1 \text { perforator based flap }\end{array}$ \\
\hline Exposed Calcaneum & 3 & $\begin{array}{l}1 \text { Lateral calcaneal artery flap, } 1 \text { Distally based fasciocutaneous posterior } \\
\text { calf flap \& } 1 \text { Distally based superficial sural artery flap }\end{array}$ \\
\hline Exposed Calcaneum with fracture & 2 & 1 Distally based superficial sural artery flap \& 1 cross leg flap \\
\hline Exposed Tendoachilles \& Medial Malleolus & 1 & 1 Distally based fasciocutaneous posterior calf flap \\
\hline
\end{tabular}

unit. Minimal donor site graft loss occurred due to minor haematomas in 5 patients of lateral calcaneal artery flap, 1 patient of distally based fasciocutaneous posterior calf flap, 1 patient of radial forearm free flap and 1 patient of cross leg flap which healed by secondary intention. Flexor carpi radialis was not exposed during the elevation of the flap. Minor distal flap necrosis occurred in 2 patients of distally based fasciocutaneous posterior calf flap, 2 patients of distally based superficial sural artery flap, and 1 patient of cross leg flap which did not require any further intervention as no important structures were exposed and graft loss was less than $2 \mathrm{~cm}$.

On long-term follow-up of the patients, we did not find any recurrent ulceration in the patients having isolated posterior heel injuries. In patients having combined injuries, two in which cross-leg flap was done, patients had episodes of trophic ulceration that were treated with conservative management with dressings and modification of footwear. Both these patients, after 2.5 years have developed deep touch sensations over the flap and are not having complaints of recurrent ulceration.

\section{DISCUSSION}

Defects over the posterior heel have been difficult to cover especially combined injuries involving the weight bearing part of the heel and require a well vascularised reconstruction having a good durability and sensation because of its location and repeated friction by footwear. There are many possible reconstructive options for this region, including skin grafts, local flaps and distant flaps [Figure 2].

\section{Criteria that were used for the selection of method of reconstruction in our study are}

- Size of defect

- Location of the defect

- Complexity of the injury i.e. exposed bone or
Tendoachilles.

- Extent of the zone of trauma.

Pre-operative Doppler study was done in all patients.

Split thickness skin graft is the method of choice when adequate soft tissue padding is present. In one patient a young boy with degloving injury with extensive skin loss over posterior heel and calf region over almost entire leg,

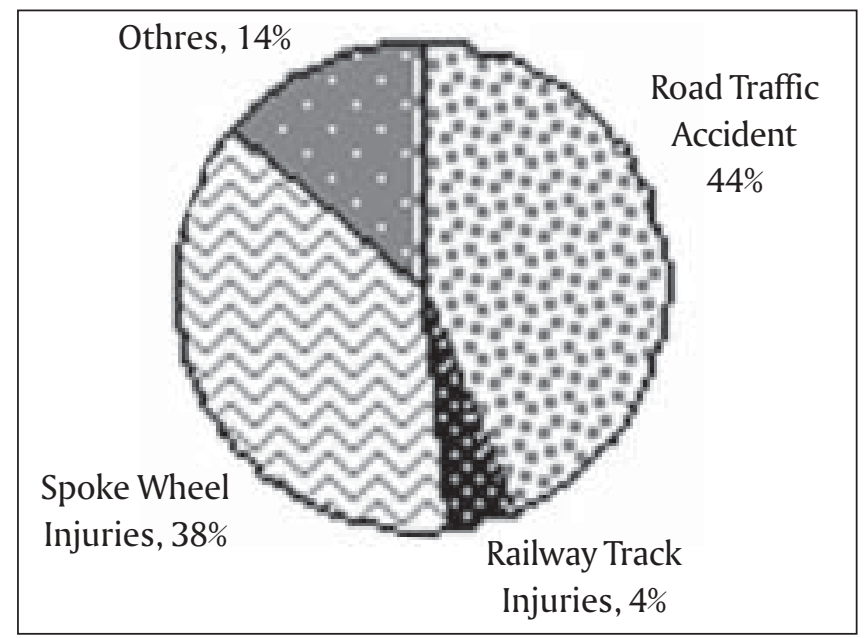

Figure 1: Pie chart - Mode of injuries

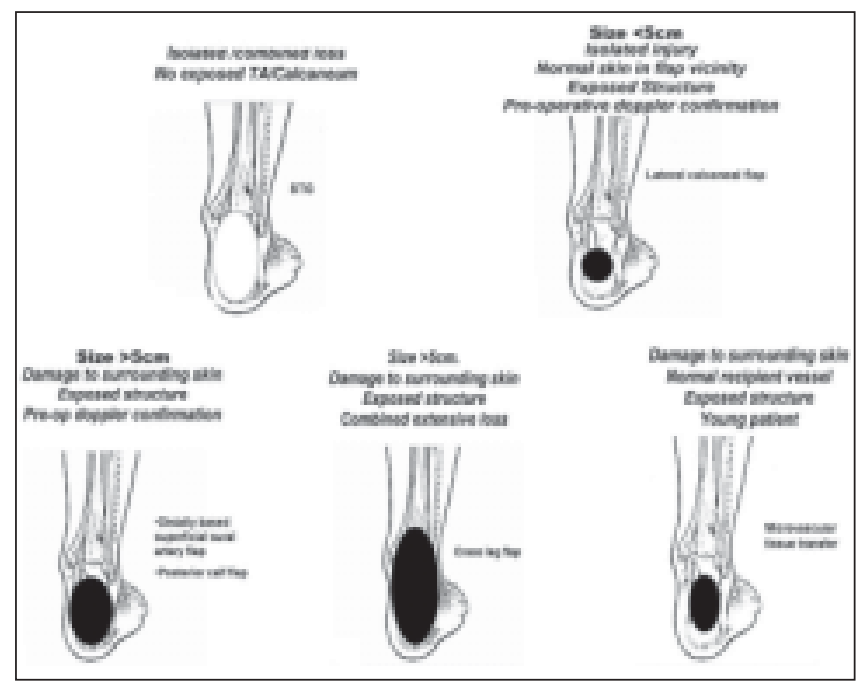

Figure 2: Our protocol of management of posterior heel injuries 
treated with Split thickness skin graft had stable and sensate reconstruction. This emphasizes that Split thickness skin graft can suffice if soft tissue padding is present and proper care is taken. The patients have shown remarkable sensory recovery over the grafted areas. In follow-up, patients treated with Split thickness skin graft were stable \& sensate.

Lateral calcaneal artery flap [Figure 3], originally described by Grabb and Argenta ${ }^{1}$ in 1981 is an axial pattern Fasciocutaneous flap that is simple, stable and sensate. It is preferred in small sized isolated posterior heel defects with exposed Tendoachilles or Calcaneum and normal skin in flap vicinity. Peroneal vessels are last to be affected by age, Diabetes mellitus or smoking, making it a safe flap in these patients. Disadvantage of the flap are that donor site requires grafting, which is put on the periosteum giving a

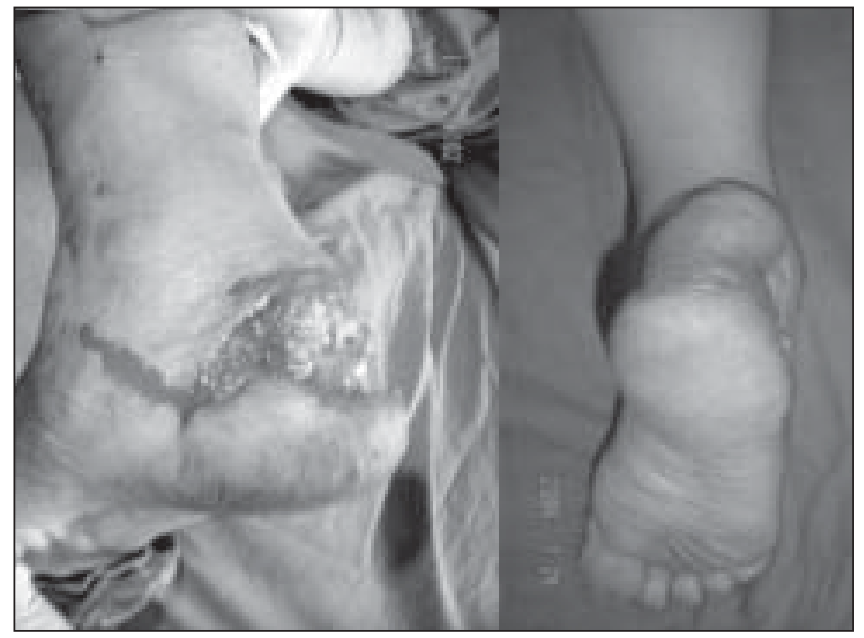

Figure 3: Lateral calcaneal artery flap in a 45 -year female patient with isolated posterior heel defect with exposed Tendoachilles, on presentation (right) and after two months follow-up (left)

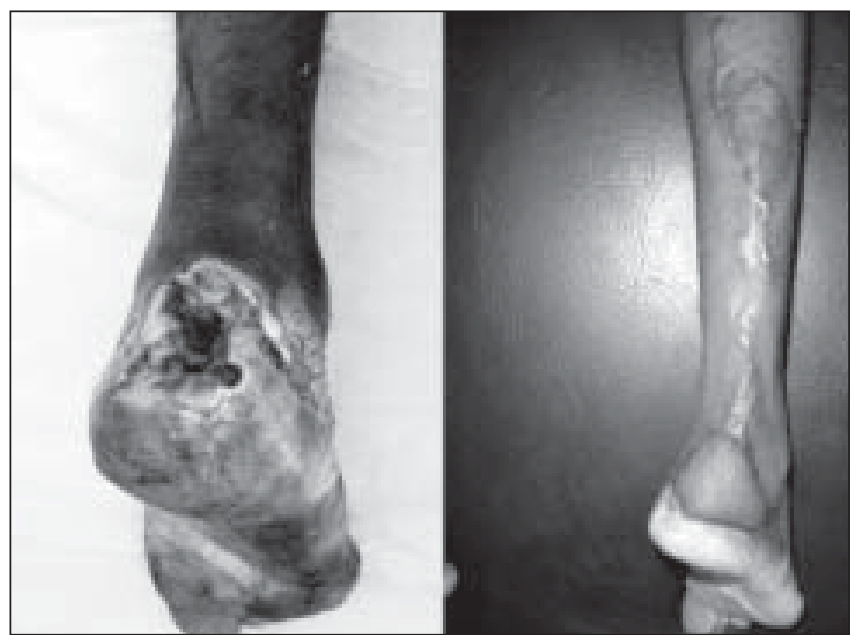

Figure 4: Distally based superficial sural artery flap in a 20 year male patient with isolated posterior heel defect with exposed Tendoachilles, Preoperative Photograph (right) and Postoperative after two months (left) depression, and causes a poor cosmetic appearance. ${ }^{2}$ Patients also have sensory disturbance at the lateral part of the dorsum of foot. In their series of seven patients Hovius et $a l^{3}$, two donor sites showed secondary healing and one donor site showed hyperkeratosis resulting from inappropriate planning of the flap. In our series of 12 patients, five of the donor sites showed minimal donor site loss which required no further intervention.

Distally based superficial sural artery flap [Figure 4], originally described by Masquelet ${ }^{4}$ in 1992 is a skin island flap that has reliable blood supply, easy and quick to elevate and major arteries are not sacrificed. This flap is useful in moderate sized Posterior heel defects with exposed Tendoachilles or Calcaneum which cannot be covered by Lateral calcaneal artery flap (size of requirement is more or if the trauma extends in to territory of lateral calcaneal

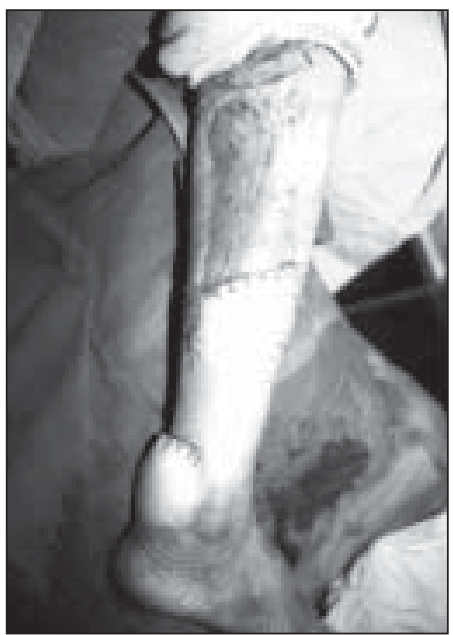

Figure 5: Intraoperative photograph of Distally based fasciocutaneous posterior calf flap

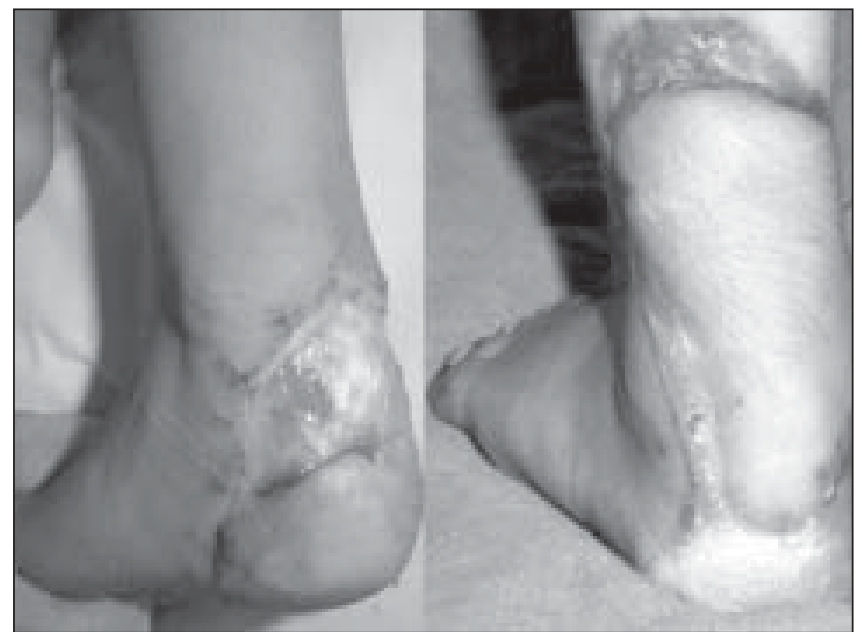

Figure 6: Perforator based posterior calf flap in a 3 year female patient isolated posterior heel defect with exposed Tendoachilles, Preoperative defect (right) and postoperative after three months (left) 


\section{Management of post-traumatic posterior heel defects}

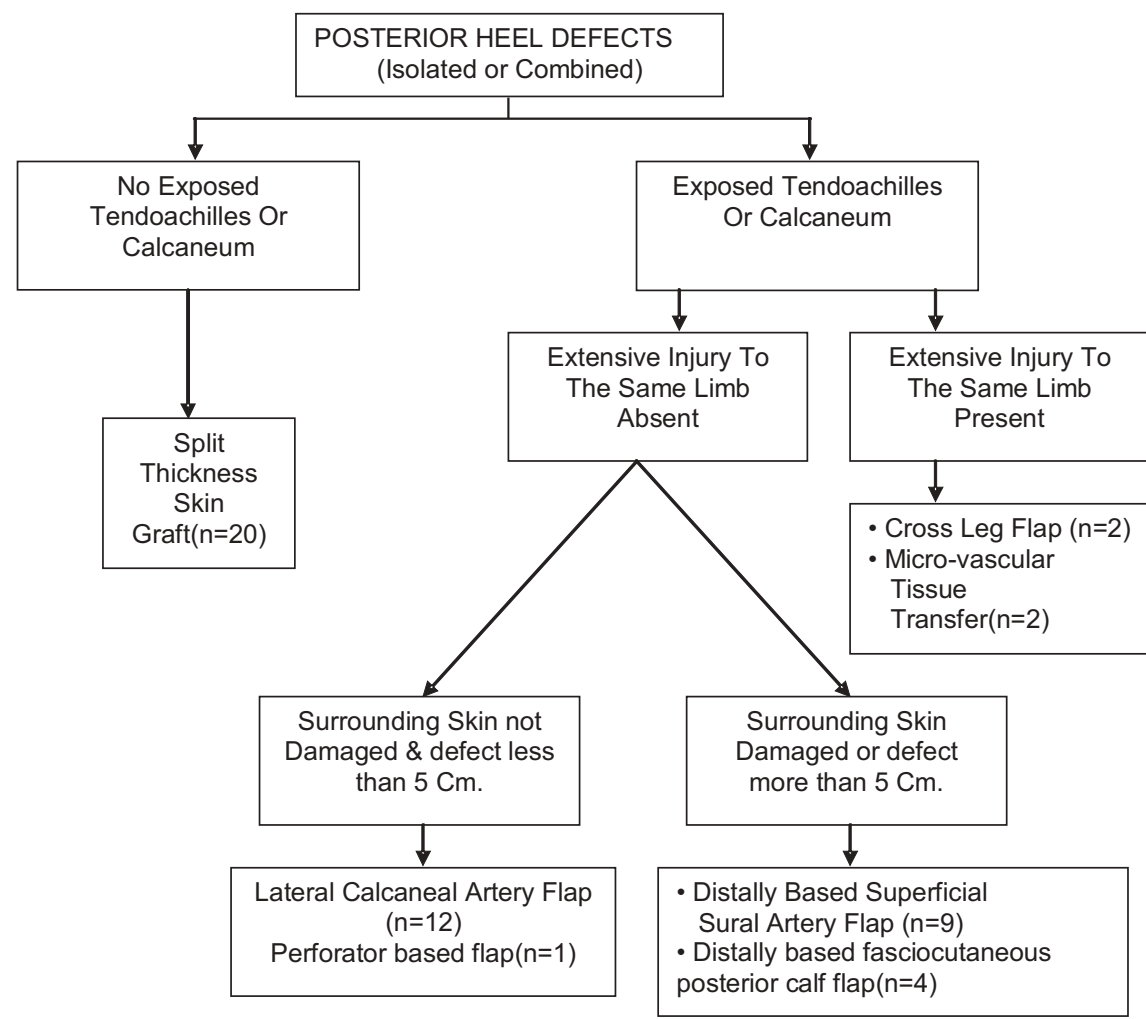

artery flap). This flap is also relatively safe in patients of Diabetes mellitus or smokers. ${ }^{5-7}$ Sacrifice of the sural nerve causes sensory loss over the lateral part of the foot. Except the inferior aesthetic appearance of donor site, loss of sensations over the lateral aspect of foot, flap does not affect the function of the limb. ${ }^{5-7}$ In their series of 17 patients Yilmaz et $\mathrm{al}^{7}$, there was marginal necrosis in one

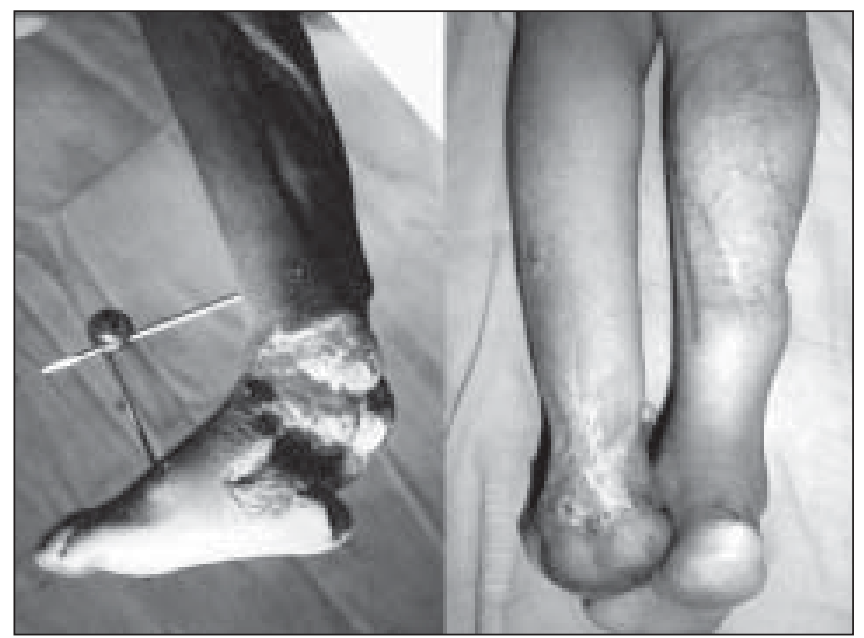

Figure 7: Cross leg flap in a patient having a combined posterior heel defect with exposed Calcaneum, Preoperative defect (right) and after 1year follow-up (left) patient and partial flap necrosis in another patient. In our series of 9 patients, we had only marginal tip necrosis in four of the patients which did not require any intervention.

Distally based fasciocutaneous posterior calf [Figure 5] which is based on perforator of peroneal or posterior tibial vessels is useful in moderate sized posterior heel defect

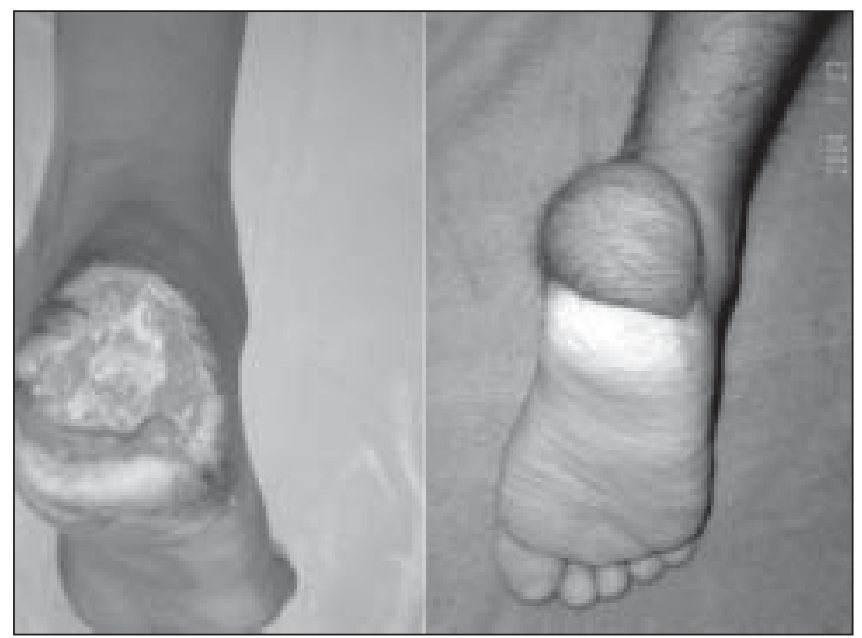

Figure 8: Anterolateral thigh skin free flap in a 16-year male patient with isolated posterior heel defect, Preoperative defect (right) and after four months follow-up 
with exposed Tendoachilles or Calcaneum. ${ }^{8}$ It has the disadvantage that it is a two-staged procedure (if not islanded). In their series of 66 islanded flaps for lower limb reconstruction, Erdmann et $\mathrm{al}^{9}$ had overall flap failure rate of $7.6 \%$ with a further $10.6 \%$ suffering from tip necrosis and haematoma formation. In our series, we had no flap failure with two out of four patients having tip necrosis and one patient suffering from minimal donor site loss from haematomas. Perforator based flap [Figure 6] can also be done and it requires preoperative Doppler confirmation. ${ }^{10}$

Cross leg flap [Figure 7] initially described by Hamilton ${ }^{11}$ in 1854 , is useful for larger flap requirement with extensive damage to the same limb and in pediatric patients with small vessel caliber. ${ }^{2}$ Disadvantages with this flap are discomfort, problems related to prolonged immobilization and long hospital stay. Free microvascular flap [Figure 8] is considered when the injury to same limb is extensive. In case of free microvascular tissue transfer for posterior heel defect reconstruction, a suitable recipient vessel is required. It has the advantage of being a single stage procedure with variety of donor sites of various sizes and avoids other disadvantages of cross leg flap.

\section{CONCLUSION}

The goal of reconstruction is to provide sensate and stable coverage for posterior heel soft tissue defect with minimal donor site morbidity. Combined defects especially involving the weight-bearing heel are difficult to cover and require a sensate flap and glabrous skin that is not possible in patients having extensive injuries. Appropriate footwear is advisable in such patients especially till the return of protective deep touch sensations.

Basic principles of wound management with wound evaluation, debridement with preservation of viable tissue, fracture reduction and fixation, prevention of infection, and early soft tissue reconstruction are important in management of posterior heel defects. The simplest appropriate technique for the reconstruction of the injured foot is likely to produce the best outcome. We present a simple management algorithm based on the size of the defect, surrounding skin condition and vascularity and complexity of defect.

\section{REFERENCES}

1. Grabb WC, Argenta LC. The lateral calcaneal artery skin flap (the lateral calcaneal artery, lesser saphenous vein, and sural nerve skin flap). Plast Reconstr Surg 1981;68:723-30.

2. Agaoglu G, Kayikciolu A, Safak T, Kecik A. Lateral calcaneal artery skin flap. Ann Plast Surg 2001;46:572-3.

3. Hovius SE, Hofman A, van der Meulen JC. Experiences with the lateral calcaneal artery flap. Ann Plast Surg 1988;21:532-5.

4. Hasegawa M, Torii S, Katoh H, Esaki S. The distally based superficial sural artery flap. Plast Reconstr Surg 1994;93:101220.

5. Raveendran SS, Perera D, Happuharachchi T, Yoganathan V. Superficial sural artery flap-a study in 40 cases. Br J Plast Surg 2004;57:266-9.

6. Costa-Ferreira A, Reis J, Pinho C, Martins A, Amarante J. The distally based island superficial sural artery flap: clinical experience with 36 flaps. Ann Plast Surg 2001;46:308-13.

7. Yilmaz $M$, Karatas $O$, Barutcu A.The distally based superficial sural artery island flap: clinical experiences and modifications. Plast Reconstr Surg 1998;102:2358-67.

8. Touam C, Rostoucher P, Bhatia A, Oberlin C. Comparative study of two series of Distally based Fasciocutaneous Flaps for coverage of the lower One-fourth of the leg, the Ankle, and the Foot Plast Reconstr Surg 2001;107:383-92.

9. Erdmann MW, Court-Brown CM, Quaba AA. A five year review of islanded distally based fasciocutaneous flaps on the lower limb. Br J Plast Surg 1997;50:421-7.

10. Taylor GI, Doyle M, McCarten G. The Doppler probe for planning flaps: anatomical study and clinical applications. Br J Plast Surg 1990;43:1-16.

11. Atiyeh BS. The cross-leg flap: a new perspective. Plast Reconstr Surg 1994;94:223-4.

12. Hudson DA, Millar. The cross-leg flap: still a useful flap in children. Br J Plast Surg 1992;45:146-9. 